Abstracta Iranica Abstracta Iranica

Revue bibliographique pour le domaine irano-aryen

Volume 29 | 2008

Comptes rendus des publications de 2006

\title{
Les derviches tourneurs. Doctrine, histoire et pratiques. Paris, Cerf, 2006, 212 p.
}

\section{Alexandre Papas}

\section{OpenEdition}

1 Journals

\section{Édition électronique}

URL : http://journals.openedition.org/abstractairanica/30302

DOI : 10.4000/abstractairanica.30302

ISSN : 1961-960X

Éditeur :

CNRS (UMR 7528 Mondes iraniens et indiens), Éditions de l'IFRI

Édition imprimée

Date de publication : 15 mai 2008

ISSN : 0240-8910

\section{Référence électronique}

Alexandre Papas, «Les derviches tourneurs. Doctrine, histoire et pratiques. Paris, Cerf, 2006, 212 p. », Abstracta Iranica [En ligne], Volume 29 | 2008, document 288, mis en ligne le 15 septembre 2008, consulté le 26 septembre 2020. URL : http://journals.openedition.org/abstractairanica/30302 ; DOI : https://doi.org/10.4000/abstractairanica.30302

Ce document a été généré automatiquement le 26 septembre 2020.

Tous droits réservés 


\title{
Les derviches tourneurs. Doctrine,
} histoire et pratiques. Paris, Cerf, 2006, $212 \mathrm{p}$.

\author{
Alexandre Papas
}

1 Une lecture rapide laisserait croire qu'il s'agirait d'un ouvrage de vulgarisation. Il n'en est rien. Au contraire, cette présentation claire et scientifique de l'ordre soufi Mevleviyye exige une érudition solide qui, se faisant discrète, donne les principales clés de compréhension au lecteur attentif. Car ce qu'ambitionne le présent ouvrage n'est pas de soumettre une ne introduction poético-spirituelle à Rumi. Non, il s'agit de décrire la vie d'un courant soufi, à partir de son maître inspirateur jusqu'à sa pratique fondamentale, en passant par son institutionnalisation. Ce type d'essai n'a été tenté que par des auteurs turcs (on pense à Abdülbaki Gölpinarli en premier lieu). Or un grand nombre de lecteurs enthousiastes de Rumi ignore le turc et, par conséquent, la masse extraordinaire de travaux publiés en Turquie. Ils en goûteront la saveur dans ce livre, sans toutefois perdre le parfum de la poétique persane rumienne grâce à une première partie, écrite par E. Feuillebois, consacrée à la vie et à l'œuvre du grand mystique. La seconde, signée Th. Zarcone, propose un large panorama historique de l'ordre apparu avec Sultan Veled (notez l'iconographie jointe qui est passionnante). La troisième partie, de la main d'A. Ambrosio, analyse en détail et de manière originale la fameuse danse des derviches. Telles sont les trois portes d'entrées permettant de comprendre le phénomène des derviches tourneurs sans tomber dans la nostalgie surannée du XIII ${ }^{\mathrm{e}} \mathrm{s}$. et sans réduire la spiritualité postmédiévale à une simple déchéance. 
INDEX

Thèmes : 8 . Soufisme

\section{AUTEURS}

ALEXANDRE PAPAS

CNRS - Paris 